\title{
Porous Ceramics Obtained with the Use of Aluminum Hydroxide Powder
}

\author{
ILYA ALEXANDROVICH ZHUKOV ${ }^{1,2}$, ELENA SERGEEVNA DEDOVA ${ }^{1,2,3}$, \\ SVETLANA PETROVNA BUYAKOVA ${ }^{1,2,3}$, SERGEY NIKOLAEVICH KULKOV ${ }^{1,2,3}$, \\ RUSLAN VIKTOROVICH LEVKOV ${ }^{1,2}$, GRIGORY MAMONTOV ${ }^{2}$ and VLADIMIR \\ PROMAKHOV ${ }^{2}$
}

\author{
${ }^{1}$ Institute of Strength Physics and Materials Science SB RAS, 2/4, \\ Akademichesky Prospekt, Tomsk, Russia, 634055. \\ ${ }^{2}$ Tomsk State University, 36, Lenin Prospekt, Tomsk, Russia, 634050. \\ ${ }^{3}$ Tomsk Polytechnic University, 30, Lenin Prospekt,Tomsk, Russia, 634050. \\ ${ }^{*}$ Corresponding Author E-mail: mtrushin@ mail.ru
}

http://dx.doi.org/10.13005/ojc/320109

(Received: June 18, 2015; Accepted: January 23, 2016)

\begin{abstract}
This work was aimed at studying the influence of structure and properties of powders of aluminum hydroxide and zirconium dioxide on the structure and properties of the obtained ceramics. The work studied $\mathrm{Al}_{2} \mathrm{O}_{3}$ ceramics obtained from aluminum hydroxide and composite materials $\mathrm{ZrO}_{2}$ $\mathrm{Al}_{2} \mathrm{O}_{3}$ obtained from mixtures of zirconium dioxide and aluminum hydroxide powders. The work shows the data about the structure and properties of the initial powders used for the production of ceramics, as well as data about the structure and properties of $\mathrm{Al}_{2} \mathrm{O}_{3}$ and $\mathrm{ZrO}_{2}-\mathrm{Al}_{2} \mathrm{O}_{3}$ ceramic materials. It has been found that increasing aluminum hydroxide content in the initial mixture with the zirconium dioxide powder leads to increasing porosity of $\mathrm{ZrO}_{2}-\mathrm{Al}_{2} \mathrm{O}_{3}$ composites sintered within the temperature range between 1,400 and $1,650^{\circ} \mathrm{C}$. It has been shown that increasing sintering temperature of the $\mathrm{Al}_{2} \mathrm{O}_{3}$ ceramics leads to increasing compressive strength from $6 \mathrm{MPa}$ to $800 \mathrm{MPa}$ at the temperature of sintering between 1,300 and $1,500^{\circ} \mathrm{C}$, respectively.
\end{abstract}

Key words: Alumina, hydroxide aluminum, zirconium dioxide, strength, porosity, composite, properties.

\section{INTRODUCTION}

Among the variety of modern materials, ceramics takes a special place due to its physical and chemical properties, such as high corrosion resistance, temperature resistance, resistance to radiation treatment, and biological compatibility ${ }^{1-5}$. Materials of aluminum oxide and composites based on it $^{6-9}$ have the greatest ability to preserve structure and properties when exposed to aggressive environments without degradation of properties, corrosion and chemical resistance, high strength. 
$\mathrm{Al}_{2} \mathrm{O}_{3}$ and $\mathrm{ZrO}_{2}-\mathrm{Al}_{2} \mathrm{O}_{3}$ ceramics with predefined porosity, size and shape of the pores, properly complies with the requirements to catalyst carriers, filters and bioimplants ${ }^{9-12}$. To date, there are many technological approaches that ensure necessary porosity in ceramics, among which the most common is the introduction of organic pore-forming additives. The main disadvantage of this method is the presence of the products of pore-forming agent blowing in the obtained porous material, namely, carbon and its compounds, which is unacceptable for medical supplies and some catalysts carriers. The method based on the use of hydroxides makes it possible to avoid the presence of impurities [13]. Analysis of literature shows that currently there is a lack of systematic studies of porous ceramics obtained with the use of hydroxides. This work was

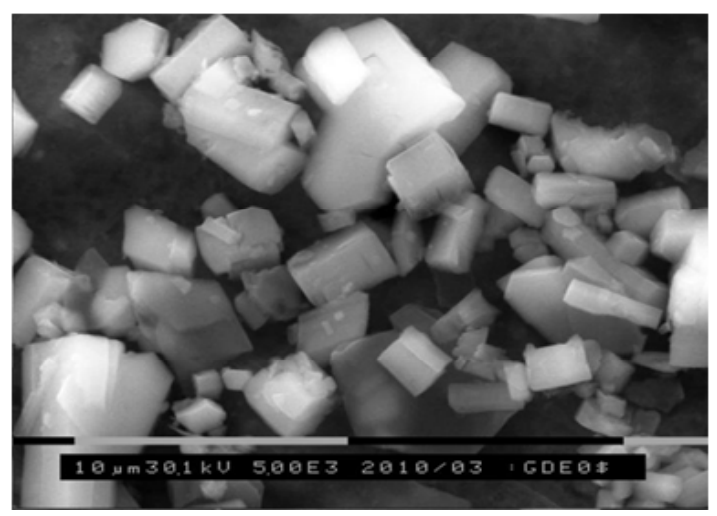

Fig. 1: SEM image of the aluminum hydroxide powder

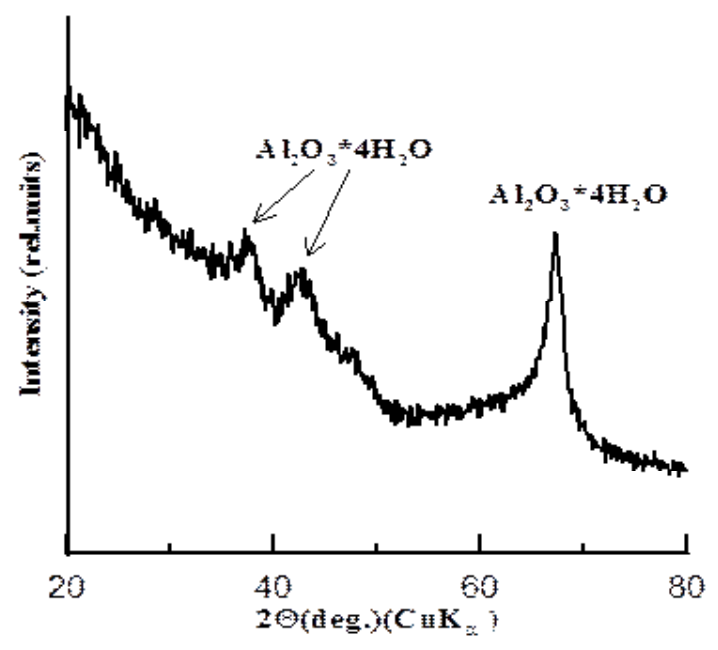

Fig. 2: X-Ray photograph of the aluminum hydroxide powder aimed at studying the influence of structure and properties of powders of aluminum hydroxide and zirconium dioxide on the structure and properties of the obtained ceramics.

\section{MATERIALS AND METHODS}

For obtaining porous $\mathrm{Al}_{2} \mathrm{O}_{3}$ ceramics, powder of hydrated aluminum oxide obtained by decomposing aluminate solution was used as the original component. For obtaining $\mathrm{ZrO}_{2}-\mathrm{Al}_{2} \mathrm{O}_{3}$ porous composite materials, a mixture of powder of zirconium dioxide obtained by chemical deposition of salts and hydrated aluminum oxide was used. The volume fraction of aluminum hydroxide mixed with zirconium dioxide was $1,5,10,25,50 \%$. The powders were pressed in a steel mold at pressure up to $200 \mathrm{MPa}$. The change in porosity of ceramics was ensured by varying the sintering temperature of the samples. The press-works of aluminum hydroxide were sintered in the open air at temperatures of 1,300,1,400,1,500 ${ }^{\circ} \mathrm{C}$ with isothermal exposure for 1 hour, press-works from a mixture of powders of zirconium dioxide and aluminum hydroxide were sintered at temperatures of $1,400,1,500,1,550,1,600,1,650^{\circ} \mathrm{C}$, in the same conditions.

X-ray studies were performed with the use of diffractometer (CuKa radiation, ë $=1.54060 \AA$, room temperature) in step mode ("ô $=0.1$, exposure 5 seconds), in the angle range $2 \mathrm{E}$ from 20 to 80 . The size of the areas of $x$-rays coherent scattering (CSA) was measured at small diffraction angles. The phase was identified by comparing the peaks of the x-ray photographs with the catalog of the American Society

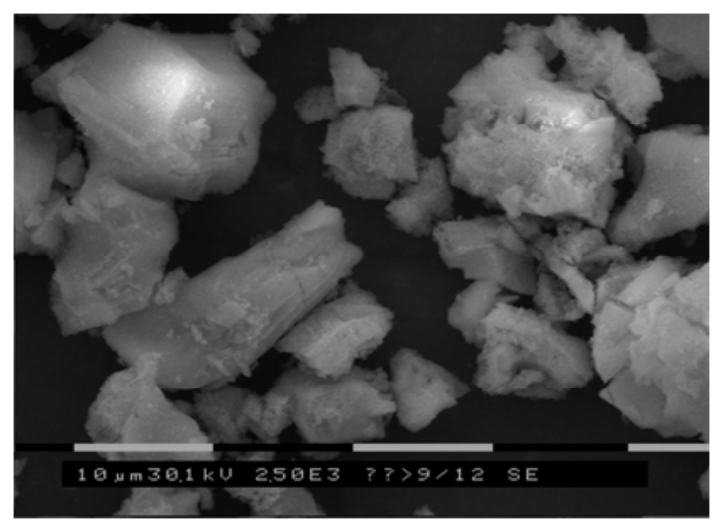

Fig. 3: SEM image of $\mathrm{ZrO}_{2}\left(\mathrm{Y}_{2} \mathrm{O}_{3}\right)$ powder 
of Testing Materials (ASTM). The content zirconium phases was assessed by the ratio of the integrated intensity of lines I (111) of the tetragonal (T) phase and I (111), I (111) of the monoclinic (M) phase.

Powder morphology and the structure of the sintered ceramics were studied with the use of a scanning electron microscope Philips SEM 515. Thermogravimetric analysis (TGA) and differential scanning calorimetry (DSC) were performed with the use of a thermoanalyzer in a platinum crucible in an inert atmosphere at temperatures between 20 and $1,300^{\circ} \mathrm{C}$. Ceramics samples were compressiontested at the "INSTRON - 1185" test installation with the loading rate of $0.2 \mathrm{~mm} / \mathrm{s}$.

\section{RESULTS}

\section{Powders}

Aluminum hydroxide powder consisted of isolated polycrystalline particles with the average size of $2.6 \mu \mathrm{m}$ with the rms (root-mean-square)

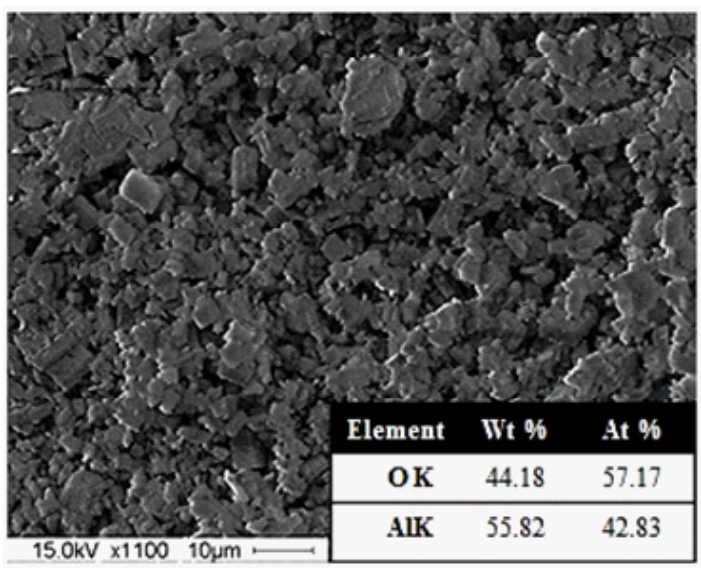

SEM image, elemental analysis of ceramic sintered at $1,300^{\circ} \mathrm{C}$. deviation of $1.5 \mu \mathrm{m}$, Figure 1. In distribution of particle by size, only one maximum was present, whereby the predominant number of particles had the size between 0.5 and $4 \mathrm{im}$, also single particles up to $8 \mathrm{~mm}$ were present. The value of specific surface area of the aluminum hydroxide powder was $173 \mathrm{~m}^{2} / \mathrm{g}$.

X-ray diffraction study showed that the aluminum hydroxide powder was represented by structural modification of $\mathrm{Al}_{2} \mathrm{O}_{3} \cdot 4 \mathrm{H}_{2} \mathrm{O}$ in the amorphous state, as evidenced by the high background at low angles of diffraction, Figure 2.

Thermal analysis showed that powder heating was accompanied by a mass loss occurring in two stages at different temperatures: 25 - 550 ${ }^{\circ} \mathrm{C}, 800-1,150{ }^{\circ} \mathrm{C}$. Mass loss was computed by the method of thermogravimetry, and amounted to Äm $=17.6 \%$. Two endothermic reflexes are present on powder DSC curve: one in the temperature range between 20 and $380{ }^{\circ} \mathrm{C}$, the second in

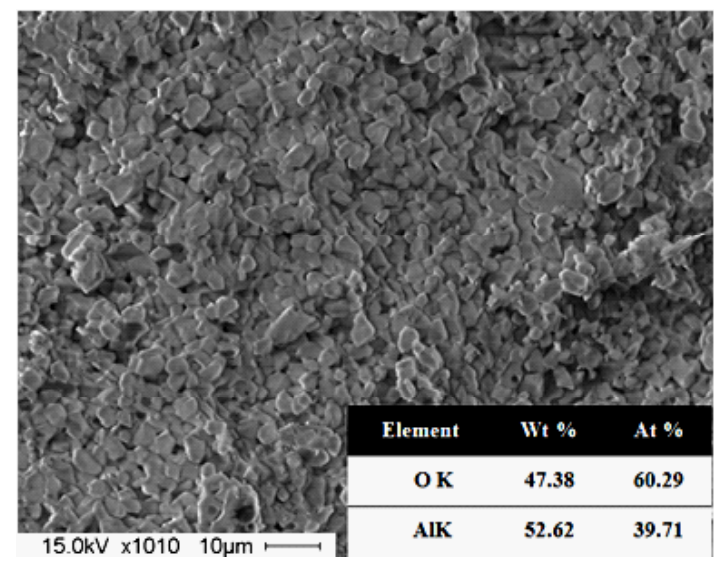

SEM image, elemental analysis of ceramic sintered at $1,500{ }^{\circ} \mathrm{C}$.

Fig. 4: A SEM image of $\mathrm{Al}_{2} \mathrm{O}_{3}$ ceramic sintered a - at $1,300{ }^{\circ} \mathrm{C}, \mathrm{b}-$ at $1,500{ }^{\circ} \mathrm{C}$

Table 1 :

\begin{tabular}{lccc}
\hline & $\mathbf{1 , 3 0 0}{ }^{\circ} \mathbf{C}$ & $\mathbf{1 , 4 0 0}{ }^{\circ} \mathbf{C}$ & $\mathbf{1 , 5 0 0}{ }^{\circ} \mathbf{C}$ \\
\hline The average particle size $(<\mathrm{d}>)$ & $<\mathrm{d}>=3.1$ & $<\mathrm{d}>=4.4$ & $<\mathrm{d}>=5.1$ \\
and the standard rms deviation $(\sigma), \mu \mathrm{m}$ & $\sigma=1.3$ & $\sigma=1.6$ & $\sigma=2.5$ \\
The average pores size $(<\mathrm{d}>)$ & $<\mathrm{d}>=2.4$ & $<\mathrm{d}>=2.2$ & $<\mathrm{d}>=1.6$ \\
and the standard rms deviation $(\sigma), \mu \mathrm{m}$ & $\sigma=3.4$ & $\sigma=0.9$ & $\sigma=1.1$ \\
Porosity, \% & 60 & 45 & 20 \\
\hline
\end{tabular}


the temperature range between 800 and 1,100 ${ }^{\circ} \mathrm{C}$, and the exothermic reflex in the temperature range between 1,100 and $1,300{ }^{\circ} \mathrm{C}$. It should be noted that the temperature intervals of the sections that correspond to decreasing powder mass are consistent with the position of the endothermic reflexes on the DSC curve.

$\mathrm{ZrO}_{2}\left(\mathrm{Y}_{2} \mathrm{O}_{3}\right)$ powder was a solid solution of composition 97 mole \% of $\mathrm{ZrO}_{2}-3$ mole \% of $\mathrm{Y}_{2} \mathrm{O}_{3}$ obtained by chemical vapor deposition. The powder consisted of dense polycrystalline agglomerates, Figure 3. According to the data obtained, type of agglomerates distribution by size is unimodal, the prevailing amount of agglomerates had a size between 1 and $12 \mu \mathrm{m}$, but agglomerates were also present with the size that reached $80 \mathrm{im}$. The average size of the agglomerates was $12 \mathrm{im}$; the average size of particles in the agglomerates was $0.2 \mathrm{im}$. The specific surface of the powder amounted to 7.6 $\mathrm{m}^{2} / \mathrm{g}$. X-ray phase analysis showed the presence of the tetragonal and monoclinic phases of zirconium dioxide powder. The content of phases was 65 and $35 \%$, respectively. The average size of CSA of the tetragonal phase was $20 \mathrm{~nm}$, and that of the monoclinic phase $-40 \mathrm{~nm}$. The value of crystalline lattice micro distortion was $2.374 \cdot 10^{-3}$, lattice parameter $\mathrm{c}=5.1849 \AA, a=5.0908 \AA$.

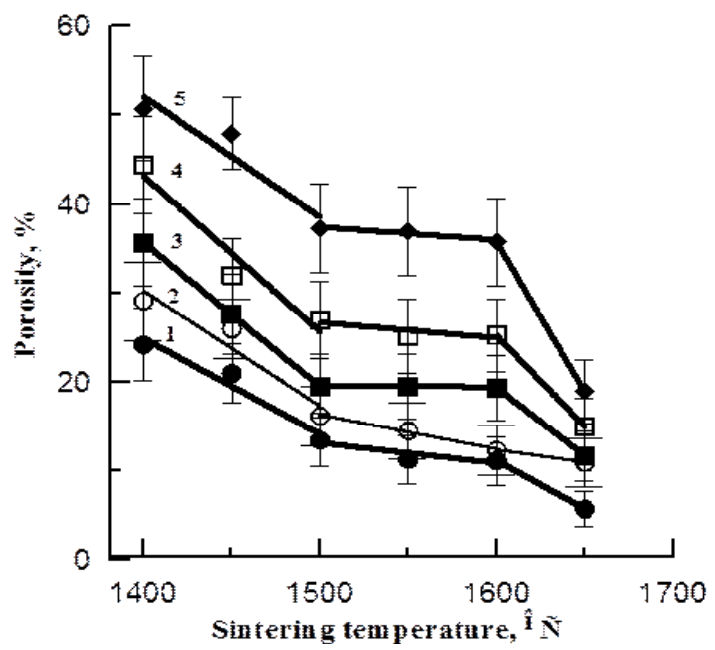

Fig. 5: Dependency of porosity on the sintering temperature of $\mathrm{ZrO}_{2}-\mathrm{Al}_{2} \mathrm{O}_{3}$ composites. The dependencies correspond to the content of aluminum hydroxide in the initial material 1 1\%, 2- 5\%, 3- 10\%, 4- $25 \%$, 5 -50\%

\section{$\mathrm{Al}_{2} \mathrm{O}_{3}$ ceramics from aluminum hydroxide}

Phase analysis of alumina ceramics sintered at $1,300{ }^{\circ} \mathrm{C}$ and above is represented by the hightemperature a modification - $\mathrm{Al}_{2} \mathrm{O}_{3}$. Ceramics sintered at $1,300^{\circ} \mathrm{C}$ is represented by grains of two types: those of irregular shape and those close to spherical shape. The average size of grains was to $3.1 \mathrm{im}$ with the average squared deviation of $1.3 \mathrm{im}$. As the sintering temperature increased, the size of aluminum oxide grains increased, too. In ceramics sintered at 1,400 and $1,500{ }^{\circ} \mathrm{C}$, the grains of aluminum oxide mostly had spherical shape. Besides, the structure of the ceramics had interparticle porosity, which decreased with increasing sintering temperature. In the ceramics studied, total porosity $(\dot{E})$ was $60 \%$ at the temperature of sintering of $1,300{ }^{\circ} \mathrm{C}$, È H" $45 \%$ at $1,400{ }^{\circ} \mathrm{C}$, and exceeded $20 \%$ for samples sintered at $1,500{ }^{\circ} \mathrm{C}$. The shrink ratio increased from $7 \%$ to $30 \%$ with the sintering temperature increasing from 1,300 to $1,500{ }^{\circ} \mathrm{C}$, respectively. The generalized data about the average size of pores and grains in $\mathrm{Al}_{2} \mathrm{O}_{3}$ ceramics are shown in Table 1. A SEM image of polished surface and elementary analysis of the obtained ceramics are shown in Figure 4.

Studying the mechanical properties of the obtained ceramic samples showed that with increasing the temperature of sintering, there is a significant increase in compressive strength from 6 $\mathrm{MPa}$ at $1,300^{\circ} \mathrm{C}$ to $800 \mathrm{MPa}$ at $1,500^{\circ} \mathrm{C}$, respectively. Increasing mechanical properties is obviously related

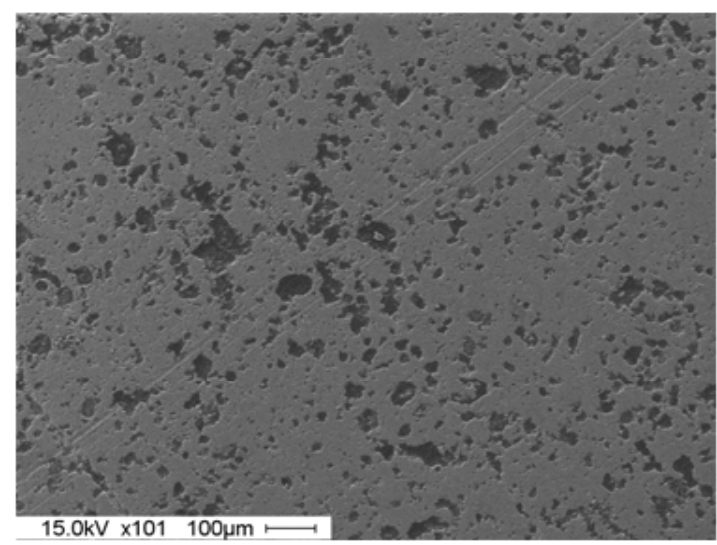

Fig. 6: A SEM image of polished surface of $\mathrm{ZrO}_{2}-\mathrm{Al}_{2} \mathrm{O}_{3}$ composites. The composites were obtained from a mixture of $50 \%$ of $\mathrm{ZrO}_{2}\left(\mathrm{Y}_{2} \mathrm{O}_{3}\right)$ and $50 \%$ of $\mathrm{Al}_{2} \mathrm{O}_{3}{ }^{*} 4 \mathrm{H}_{2} \mathrm{O}$, the temperature of sintering was $1,500{ }^{\circ} \mathrm{C}$ 
to reduction of porosity of sintered ceramics, and, consequently to density increase.

\section{$\mathrm{ZrO}_{2}-\mathrm{Al}_{2} \mathrm{O}_{3}$ composite materials}

Figure 5 shows the dependence of porosity in $\mathrm{ZrO}_{2}-\mathrm{Al}_{2} \mathrm{O}_{3}$ composite materials on the temperature of their sintering. The figure shows that regardless of the initial powder mixture composition, increasing sintering temperature was accompanied by a decrease in the pore volume in the composites. The increase in the volume fraction of aluminum hydroxide in powder mixtures was accompanied by an increase in porosity in the resulting composites. Whereby, in the composites sintered in the temperature range between 1,500 and $1,600{ }^{\circ} \mathrm{C}$, the volume fraction of pores was almost unchanged. Analysis of pores' average size in $\mathrm{ZrO}_{2}-\mathrm{Al}_{2} \mathrm{O}_{3}$ composites sintered at 1,400 ${ }^{\circ} \mathrm{C}$, depending on the volume fraction of aluminum hydroxide in the initial powder mixture, showed that with increasing the volume fraction of aluminum hydroxide, the average pore size increased from 7 to $18 \mathrm{im}$, with increasing the volume fraction of aluminum hydroxide in the initial material from $1 \%$ to $50 \%$, respectively. A SEM image of the polished surface of $\mathrm{ZrO}_{2}-\mathrm{Al}_{2} \mathrm{O}_{3}$ ceramics is shown in Figure 6.

According to $x$-ray studies, the phase composition of the obtained $\mathrm{ZrO}_{2}-\mathrm{Al}_{2} \mathrm{O}_{3}$ composites is represented by tetragonal and monoclinic modifications of $\mathrm{ZrO}_{2}$ and high-temperature modification a $-\mathrm{Al}_{2} \mathrm{O}_{3}$. With that, there was a difference in the shares of the high-temperature tetragonal and the low-temperature monoclinic modifications of zirconium dioxide, depending on the ratio of zirconium oxide and aluminum hydroxide in the powder mix and the composites sintering temperature. According to the obtained data, regardless of the amount of aluminum hydroxide in the initial mix, increasing sintering temperature was accompanied by the reduction in the share of tetragonal phase of zirconium dioxide in $\mathrm{ZrO}_{2}-\mathrm{Al}_{2} \mathrm{O}_{3}$ porous composites. With that, in the temperature range of composites sintering between 1,400 $1,550^{\circ} \mathrm{C}$, the share of tetragonal phase of zirconium dioxide decreased on the average from 70 to $25 \%$ and remained unchanged with increasing the temperature of sintering to $1,650^{\circ} \mathrm{C}$.
Analysis of the influence of CSA size of the tetragonal phase of zirconium dioxide on the porosity of the composites showed that with decreasing the size of CSA of the tetragonal phase, the porosity of the composites decreases. With extrapolation of the approximating function on the non-porous state, the CSA size of the tetragonal phase of zirconium dioxide in the composite is $65 \mathrm{~nm}$. The composites with $7 \%$ porosity had the greatest tensile strength of $1,100 \mathrm{MPa}$.

\section{DISCUSSION}

The presence of the first endothermic reflex on the calorimetric curve of aluminum hydroxide powder is associated with removing moisture adsorbed on the particles surface and structured î́ groups, the second endothermic reflex corresponds to transformation of hydrated aluminum oxide into the low-temperature $\mathrm{g}-\mathrm{Al}_{2} \mathrm{O}_{3}$. The presence of the exothermic reflex on the DSC curve is associated with structural transformation of the lowtemperature modification of aluminum oxide into the high-temperature modification a of $\mathrm{Al}_{2} \mathrm{O}_{3}$. The x-ray photograph of aluminum hydroxide powder subjected to annealing at $1,300^{\circ} \mathrm{C}$ had only the reflexes of the high-temperature a modification - $\mathrm{Al}_{2} \mathrm{O}_{3}$.

Work ${ }^{14}$ describes the nature of zirconium dioxide and its solid solutions. The authors of this work report that from the practical point of view interesting are only the solid solutions of various oxides based on $\mathrm{ZrO}_{2}$, or mechanical mixture with a rigid matrix that are capable of stabilizing the hightemperature phases of $\mathrm{ZrO}_{2}$ at low temperature. At room temperature, $\mathrm{ZrO}_{2}$ is in the monoclinic phase, and when heated, it experiences phase transformations: $\mathrm{m}$ (monoclinic modification) - $\mathrm{ZrO}_{2}$ $\rightarrow\left(1,197^{\circ} \mathrm{C}\right) \rightarrow \mathrm{t}$ (tetragonal) $\mathrm{ZrO}_{2} \rightarrow\left(2,300^{\circ} \mathrm{C}\right) \rightarrow$ $\mathrm{c}$ (cubic) $\mathrm{ZrO}_{2} \rightarrow\left(2,600^{\circ} \mathrm{C}\right) \rightarrow$ melting. Transition $\mathrm{t}$ $\mathrm{ZrO}_{2} \rightarrow \mathrm{C}-\mathrm{ZrO}_{2}$ has diffusive nature and plays a very important role in manufacturing the so-called partially stabilized zirconium dioxide. Transformation $\mathrm{m}-\mathrm{ZrO}_{2}$ $\rightarrow \mathrm{t}-\mathrm{ZrO}_{2}$ proceeds by a martensitic mechanism, and is accompanied by volumetric change by $5-9$ $\%$. Such a significant material expansion in course of cooling is accompanied by cracking, and makes it impossible to obtain compact products of pure $\mathrm{ZrO}_{2}$. It has been found that $\mathrm{ZrO}_{2}$ can form solid solutions of substitution type with several two-, 
three - and tetravalent oxides. The common and very important for the ceramic technology feature of these solid solutions is the absence of reversible polymorphic transformations of type $\mathrm{m}-\mathrm{ZrO}_{2} \rightarrow$ $\mathrm{t}-\mathrm{ZrO}_{2}$ transition in pure $\mathrm{ZrO}_{2}$. Although the formed solid solutions are not thermodynamically balanced at low temperatures, in practice they can exist at these temperatures without disintegrating. Therefore, $\mathrm{ZrO}_{2}$ exists only at very high temperatures, due to significant thermal vibrations of the crystalline lattice. When the temperatures decreases, the diffusion transition c - $\mathrm{ZrO}_{2} \rightarrow \mathrm{t}-\mathrm{ZrO}_{2}$ occurs. Tetragonal $\mathrm{ZrO}_{2}$, like cubic $\mathrm{ZrO}_{2}$ has the fluorite type structure. With further decrease in temperature, when the diffusion is practically finished, and the tightness of oxygen ions increases, martensitic transformation of $\mathrm{t}-\mathrm{ZrO}_{2}$ $\rightarrow \mathrm{m}-\mathrm{ZrO}_{2}$ occurs. Expansion of the oxygen position that promotes creation of stable fluorite structure in a wide range of temperatures can be achieved either by partial substitution of $\mathrm{ZrO}_{2}{ }^{4+}$ ions with the ions of larger radius, or by creating vacancies in the anion sublattice by replacing $\mathrm{ZrO}_{2}{ }^{4+}$ with ions of lower valence. Small size of the ion radius is less favorable for stability of these solid solutions. In addition to formation of solid solutions based on $\mathrm{ZrO}_{2}$, another type of stabilization of high temperature modification of $\mathrm{t}-\mathrm{ZrO}_{2}$ is used in the production of high-strength ceramics. After sintering the mechanical mixture of $\mathrm{Al}_{2} \mathrm{O}_{3}-\mathrm{ZrO}_{2}$ with volumetric content of $\mathrm{ZrO}_{2}$ of less than $20 \%$, a rigid corundum matrix is formed that holds the dispersed inclusions of $\mathrm{t}-\mathrm{ZrO}_{2}$. This is explained by higher elasticity modulus of corundum and lower thermal expansion, as compared to $\mathrm{ZrO}_{2}$. Therefore, $\mathrm{t}-\mathrm{ZrO}_{2}$ particles are in the field compressive stress, and remain stable after the sintered material is cooled. The $\mathrm{t}-\mathrm{ZrO}_{2}$ particles stability also depends on their size: unalloyed grains $\mathrm{t}-\mathrm{ZrO}_{2}$ in the corundum matrix are transformed into $\mathrm{m}-\mathrm{ZrO}_{2}$ at $20^{\circ} \mathrm{C}$ if their size exceeds $0.6 \mathrm{im}$. Coarser grains are transformed at higher temperatures, as compared to finer ones. The possibility of obtaining high-strength zirconium ceramic is related to the discovery of the so-called transformational hardening due to controlled phase transition $\mathrm{t}-\mathrm{ZrO}_{2} \mathrm{O}_{2}$. The essence of this effect stems from the phenomenon of $\mathrm{ZrO}_{2}$ polymorphism, hightemperature $\mathrm{t}$ - and $\mathrm{c}$ - phases' ability to stabilize, and the martensitic $t \rightarrow m$ transition. Practically, the effect of transformation hardening is implemented in the case where the sintered material is composed of $\mathrm{t}-\mathrm{ZrO}_{2}$ particles that can transform into $\mathrm{m}-\mathrm{ZrO}_{2}$. The cracks occurring under loading spread until t - $\mathrm{ZrO}_{2}$ occur in their front. Such a particle in a compressed state (corundum matrix), or coherently bound with the matrix (with the predominance of $\mathrm{c}-\mathrm{ZrO}_{2}$ in the material) is resistive to the $t$ '! $m$ transition even at low temperatures. After getting into the stress field in the top of a propagating crack, the particle gains energy sufficient for transformation. Thus, the energy of the propagating cracks is transferred to the energy of the $t$ '! $m$ transition, and the catastrophic growth of the crack stops.

From the data in work ${ }^{14}$ it follows that the important property of the $\mathrm{ZrO}_{2}-\mathrm{Al}_{2} \mathrm{O}_{3}$ composites is the amount of tetragonal phase of zirconium dioxide. One of the factors that influenced the proportion of tetragonal and monoclinic modification of zirconium dioxide in obtained $\mathrm{ZrO}_{2}-\mathrm{Al}_{2} \mathrm{O}_{3}$ composites could be the individual grains of the tetragonal phase of zirconium dioxide that reached the "critical" size. It is known that for the tetragonal phase of $\mathrm{ZrO}_{2}$ there is the concept of the "critical" grain size, upon reaching of which, a spontaneous tetragonal-monoclinic transformation occurs. The value of the "critical" grain size, according to the data ${ }^{15-17}$ depends on chemical composition of the solid solution, and is $1.2 \mathrm{im}$ for the $\mathrm{ZrO}_{2}-\mathrm{Y}_{2} \mathrm{O}_{3}$ system. However, work ${ }^{17}$ shows that the value of the "critical" grain size of the tetragonal modification in ceramics decreases with increasing porosity, and is only 0.2 microns at $30 \%$. This is due to the decreasing level of elastic stresses generated by adjacent grains and constraining tetragonalmonoclinic transformation that occurs with the unit cell volume increase. For grains with a limited number of neighbors in case of large porosity, the probability of transition from the high temperature tetragonal modification of zirconium dioxide into the monoclinic low-temperature modification during cooling from the sintering temperature is high. Apparently, increasing the sintering temperature of the $\mathrm{ZrO}_{2}-\mathrm{Al}_{2} \mathrm{O}_{3}$ composites obtained in the work was accompanied by grain growth, and achieving the "critical" size of $\mathrm{ZrO}_{2}$ tetragonal phase - by individual grains.

In addition to the sintering temperature and $\mathrm{ZrO}_{2}$ grain size, the ratio of high-temperature and low-temperature modifications of $\mathrm{ZrO}_{2}$ in the $\mathrm{ZrO}_{2}-\mathrm{Al}_{2} \mathrm{O}_{3}$ composites is, apparently, could be influenced by the presence of $\mathrm{Al}_{2} \mathrm{O}_{3}$. As shown above, for $\mathrm{ZrO}_{2}$ composites with the content of aluminum 
hydroxide in the initial mixture equal to 25 and 50 $\%$, which corresponds to $\mathrm{Al}_{2} \mathrm{O}_{3}$ content in sintered ceramics of $21 \%$ and $42 \%$, respectively, the amount of tetragonal phase of zirconium dioxide decreased sharply at the sintering temperatures of over 1,500 ${ }^{\circ} \mathrm{C}$. This phenomenon could also be caused by formation of the $\mathrm{Y}_{3} \mathrm{Al}_{5} \mathrm{O}_{12}$ chemical compound, named yttrium-aluminum garnet. Work ${ }^{18}$ shows that, regardless of the composition of the mixture, the interaction of yttrium oxide and aluminum oxide starts at the temperature of $900-950{ }^{\circ} \mathrm{C}$, with formation of the $\mathrm{Y}_{4} \mathrm{Al}_{12} \mathrm{O}_{9}$ compound, at $1,100{ }^{\circ} \mathrm{C}$, formation of $\mathrm{YAIO}_{3}$ is observed, and starting with the temperature of $1,300{ }^{\circ} \mathrm{C}$, yttrium-aluminum garnet $\mathrm{Y}_{3} \mathrm{Al}_{5} \mathrm{O}_{12}$ is crystallized. Thus, in a $\mathrm{Y}_{2} \mathrm{O}_{3}$ $\mathrm{Al}_{2} \mathrm{O}_{3}$ system, at temperatures above $1,300{ }^{\circ} \mathrm{C}$, regardless of the mixture composition, it is possible to form the stable $\mathrm{Y}_{3} \mathrm{Al}_{5} \mathrm{O}_{12}$ compound [19]. Since the stabilized zirconium dioxides are solid substitution solutions, the process of destabilization occurs by disintegration of solid solutions into oxide systems that are components thereof. The products of disintegration are a monoclinic phase of zirconium oxide, the oxide of the stabilizing element, and the intermediate oxide compound of zirconium dioxide and the stabilizing element. Formation of yttrium-aluminum garnet in the $\mathrm{ZrO}_{2}-\mathrm{Al}_{2} \mathrm{O}_{3}$ composite materials could, apparently, lead to destabilization of the high temperature crystalline modification of zirconium dioxide. However, in the x-ray photographs of $\mathrm{ZrO}_{2}-\mathrm{Al}_{2} \mathrm{O}_{3}$ composites, reflexes belonging to composites could not be detected due to low content of yttrium oxide in the system.

In course of extrapolation onto a dense state, the maximum compression strength of the composites is $1,300-2,400 \mathrm{MPa}$; these values are consistent with the data shown in $\mathrm{in}^{20,21}$.

\section{CONCLUSION}

Thus, in course of the study, the structure and properties of porous $\mathrm{Al}_{2} \mathrm{O}_{3}$ and $\mathrm{ZrO}_{2}-\mathrm{Al}_{2} \mathrm{O}_{3}$ ceramics obtained with the use of aluminum hydroxide have been studied. The required porosity value in $\mathrm{Al}_{2} \mathrm{O}_{3}$ ceramics was achieved by varying the temperature of samples sintering. It has been found that increasing aluminum hydroxide content in the initial mixture with the zirconium dioxide powder leads to increasing porosity of $\mathrm{ZrO}_{2}-\mathrm{Al}_{2} \mathrm{O}_{3}$ composites sintered within the temperature range between 1,400 and $1,650{ }^{\circ} \mathrm{C}$. It has been shown that the structure of $\mathrm{Al}_{2} \mathrm{O}_{3}$ ceramics had interparticle porosity, which decreased with increasing the temperature of sintering, wherewith the limit of the compressive strength increased with increasing the temperature of sintering. It was found that nonporous state of composite $\mathrm{ZrO}_{2}-\mathrm{Al}_{2} \mathrm{O}_{3}$ materials is achieved when the size of crystallite is $65 \mathrm{~nm}$. In subsequent works, it is planned to continue studying porous ceramics obtained by the use of aluminum hydroxide powders of various modifications. It is planned to study properties like thermal conductivity and thermal-expansion coefficient in the obtained porous ceramics.

\section{ACKNOWLEDGMENTS}

Financial support from the Grant of the President RF No. MK - 5681.2014.8, No.MK - 5883.2014.8 is gratefully acknowledged.This research carried out in 2015 was supported by «The Tomsk State University Academic D.I. Mendeleev Fund Program» grant ${ }^{1}$ 8.2.46.2015.This work was supported in part by the Russian Governmental Decree 218 (State Contract No. 4678).

\section{REFERENCES}

1. Khattab, R.M., Wahsh, M.M.S., \& Khalil, N.M.. Preparation and characterization of porous alumina ceramics through starch consolidation casting technique. Ceramics International, 2012.,38(6), 4723-4728.

2. Wang, J., \& Stevens, R. (1989). Review
Zirconia-toughend alumina (ZTA) ceramics. Journal of materials science, 3421 - 3440.

3. Lukin, E.S., Makarov, N.A., \& Tarasova, S.V. New ceramic materials based on aluminum oxide. Ogneup. Tekh. Keram., 2001., 7, 2-10. 
4. Kibbel, B.W., \& Heuer, A.H. Science and Technology of Zirconia II. Advances in Ceramics, 1984. 12, 415.

5. Fan, X., Case, E.D., Ren, F., Shu, Y., \& Baumann, M.JPart II: Fracture strength and elastic modulus as a function of porosity for hydroxyapatite and other brittle materials. Journal of the mechanical behavior of biomedical materials, . 2012. 8, 99-110.

6. Pabst, W., Gregorová, E., \& Èerný, M.. Isothermal and adiabatic Young's moduli of alumina and zirconia ceramics at elevated temperatures. Journal of the European Ceramic Society, 2013.,.33(15), 3085-3093.

7. Živcová-Vlèková, Z., Locs, J., Keuper, M., Sedláøová, I., \& Chmelíèková, M. Microstructural comparison of porous oxide ceramics from the system $\mathrm{Al}_{2} \mathrm{O}_{3}-\mathrm{ZrO}_{2}$ prepared with starch as a pore-forming agent. Journal of the European Ceramic Society, 2012. 32(10), 2163-2172.

8. Abden, M.J., Afroze, J.D., Mamun, M.A., \& Haque, M.M. Microstructure and mechanical properties of $\mathrm{ZrO}_{2}-40 \mathrm{wt} \% \mathrm{Al}_{2} \mathrm{O}_{3}$ composite ceramics. Materials Express, 2014. 4(4), 317323.

9. Pabst, W., Gregorová, E., Sedláøová, I., \& Ėerný, M.. Preparation and characterization of porous alumina-zirconia composite ceramics. Journal of the European Ceramic Society, 2011 31(14), 2721-2731.

10. Ohji, T., \& Fukushima, M. Macroporous ceramics: processing and properties. International Materials Reviews, 2012. 57(2), 115-131.

11. Jiang, B., Hu, X., \& Huang, Z. Porous bioceramic coating on zirconia formed through freeze-drying. Materials Letters, 2013. 109, 66-69.

12. Isobe, T., Tomita, T., Kameshima, Y., Nakajima, A., \& Okada, K. Preparation and properties of porous alumina ceramics with oriented cylindrical pores produced by an extrusion method. Journal of the European Ceramic Society, 2006. 26(6), 957-960.
13. Deng, Z.Y., Fukasawa, T., Ando, M., Zhang, G.J., \& Ohji, T. Microstructure and mechanical properties of porous alumina ceramics fabricated by the decomposition of aluminum hydroxide. Journal of the American Ceramic Society, 2001. 84(11), 2638-2644.

14. Matryonin, S.V., \& Slosman, A.I. (2004). Technical ceramics. Tutorial (pp. 75). Tomsk: TPU Publishing house.

15. Faga, M.G., Vallée, A., Bellosi, A., Mazzocchi, M., Thinh, N.N., Martraand, \& Coluccia, G.S.,Chemical treatment on alumina-zirconia composites inducing apatite formation with maintained mechanical properties. Journal of the European Ceramic Society, . 2012. 32(10), 2113-2120.

16. Cesari, F., Esposito, L., Furgiuele, F.M., Maletta, C., \& Tucci, A. Fracture toughness of alumina-zirconia composites. Ceramics International, 2006. 32(3), 249-255.

17. Buyakova, S.P. Properties, structure, phase composition and regularities of porous nanosystems formation on the basis of $\mathrm{ZrO} 2$ (Synopsis from thesis of Doctor of Technical Sciences), Tomsk. (2008).

18. Waku, Y., Sakata, S., Mitanni, A., \& Shimizu, K.. Temperature dependence of ûexural strength and microstructure of $\mathrm{Al}_{2} \mathrm{O}_{3} / \mathrm{Y}_{3} \mathrm{Al}_{5} \mathrm{O}_{12} /$ $\mathrm{ZrO}_{2}$ ternary melt growth composites. Journal of Materials Science 2002,37, 2975-2982.

19. Keint, M.L., \& Roy, R. Structural relations among double oxides of trivalent elements. American Mineralogist, 1954. 39, 1 and 2, 1-22.

20. Meille, S., Lombardi, M., Chevalier, J., \& Montanaro, L. Mechanical properties of porous ceramics in compression: On the transition between elastic, brittle, and cellular behavior. Journal of the European Ceramic Society, 2012. 32(15), 3959-3967.

21. Zhang, J., Liao, Y., Li, W., Zhao, Y., \& Zhang, C. Microstructure and mechanical properties of glass-infiltrated Al, Of /ZrO, nanocomposites. Journal of Materials Science: Materials in Medicine, 2012. 23(2), 239-244. 